\title{
La pedagogía del oprimido: una relectura pedagógica
}

\section{The pedagogy of the oppressed: a pedagogical rereading}

\section{A pedagogia do oprimido: uma releitura pedagógica}

Carlos Ernesto Noguera-Ramírez*

\section{Resumen}

Teniendo en cuenta la amplísima literatura sobre la pedagogía del oprimido, el presente texto se propone realizar una lectura desde una dimensión poco abordada o, por lo menos, aminorada en las lecturas más frecuentemente disponibles: justamente su dimensión pedagógica. Un intento como el propuesto aquí significa releer el libro de Freire desde el horizonte conceptual de la pedagogía y ello implica desplazar (no negar) el carácter eminentemente político otorgado a la pedagogía del oprimido y recuperar sus vínculos estrechos con el pensamiento y la tradición pedagógica occidental. En particular, la relectura de la obra cumbre de Freire en clave pedagógica implica un triple trabajo: primero, localizarla dentro de una antigua tradición según la cual la politeia se entiende, en lo fundamental, como paideia; segundo, resaltar que el proceso de liberación a través de la educación solo puede realizarse mediante un proceso de concientización que lo coloca en un horizonte gnoseológico o epistémico: tránsito que el oprimido debe llevar a cabo desde la doxa hacia el logos; tercero, reconocer que el fin de la educación liberadora es la humanización de los hombres (oprimidos y opresores) y, en esa medida, se trata de una cuestión claramente "antropotécnica".

Palabras-clave: Pedagogía. Antropotécnica. Concientización. Humanización.

\section{Abstract}

Taking into account the vast literature on the pedagogy of the oppressed, the present text sets out to carry out a reading from a dimension that is little addressed or, at least, reduced in the most available readings: precisely its pedagogical dimension. An attempt like the one proposed here means rereading Freire's book from the conceptual horizon of pedagogy and this implies displacing (not denying) the eminently political character given to the pedagogy of the oppressed and recovering its close links with Western pedagogical thought and tradition. In particular, the rereading of Freire's masterpiece in pedagogical terms involves a triple task: first, locating it within an ancient tradition according to the quality of politeia understood, fundamentally, as paideia; second, highlighting the process of liberation through education can only be achieved through a process of conscientization that is placed on a gnoseological or epistemic horizon: transit that the oprimido must carry out from the doxa to the logos; third, to recognize the end of liberating education is the humanization of men and, to that extent, it is a clearly an"anthropotechnical" issue.

Keywords: Pedagogy. Anthropotechnic. Conscientization. Humanization.

Recebido em 04/08/2020 - Aprovado em 28/09/2020

http://dx.doi.org/10.5335/rep.v27i3.12366

Doctor en Educación (UFRGS) y Profesor Titular Universidad Pedagógica Nacional de Colombia. Miembro del grupo de investigación Historia de las Prácticas Pedagógicas en Colombia y de la Sociedad Colombiana de Pedagogía. ORCID: http://orcid.org/0000-0001-9848-0724. E-mail: cnoguera@pedagogica.edu.co 


\section{Resumo}

Levando em conta a vasta literatura sobre a pedagogia do oprimido, o presente texto se propõe a realizar uma leitura desde uma dimensão pouco abordada ou, pelo menos, reduzida nas leituras mais frequentes disponíveis: justamente sua dimensão pedagógica. Uma tentativa como a proposta aqui significa reler o livro de Freire desde um horizonte conceitual da pedagogia, e isso implica deslocar (não negar) o caráter eminentemente político outorgado à pedagogia do oprimido e recuperar seus vínculos estreitos com o pensamento e a tradição pedagógica ocidental. Em especial, a releitura da obra-prima de Freire em chave pedagógica implica um trabalho triplo: primeiro, localizá-la dentro de uma tradição antiga segundo a qual se compreende a politeia fundamentalmente como paideia; segundo, ressaltar que o processo de libertação através da educação só pode realizar-se mediante um processo de conscientização que o coloca em um horizonte gnosiológico ou epistêmico: trânsito que o oprimido deve levar a cabo da doxa até o logos; terceiro, reconhecer que a finalidade da educação libertadora é a humanização dos homens (oprimidos e opressores) e, nessa medida, se trata de uma questão claramente "antropotécnica".

Palavras-chave: Pedagogia. Antropotécnica. Conscientização. Humanização.

\section{Introducción}

La pedagogía del oprimido se ha traducido a más de treinta idiomas y sólo en Brasilla editorial que realizó la primera impresión ya completó su quincuagésima edición. Fue publicada inicialmente en lengua inglesa en 1970, en los Estados Unidos, pero sólo se conoció en Brasil hasta 1974 después de su publicación en español, italiano, alemán, griego, francés, holandés y portugués en Portugal (ARAÚJO, 2017). Desde las "primeras palabras" queda claro el talante de la obra y el tono general de la escritura freireana: no es el fruto de unos "devaneos intelectuales" ni sólo el resultado de lecturas, por más importantes que ellas hayan sido, nos aclara su autor: consiste en una reflexión sobre situaciones concretas, de observaciones sobre varios años de una práctica educativa claramente comprometida con un proyecto revolucionario de transformación social en cuyo horizonte está "la liberación de los hombres".

Se trata de un nuevo propósito pedagógico para el cual fue necesario construir un nuevo vocabulario. A diferencia de otras obras sustentadas en disciplinas como la psicología, la biología, la sociología, Freire prefirió utilizar en sus libros, menos un lenguaje académico que un discurso literario cercano al género epistolar y a la oralidad (él mismo calificó algunos de sus trabajos como "libros hablados") en el que prevalecen ideas de varios pensadores provenientes de diferentes corrientes filosóficas, principalmente de la fenomenología. Su estilo, no obstante, en nada resta importancia a su trabajo como lo muestra el hecho de ser reconocido por la UNESCO como uno de los grandes educadores del siglo XX (GERHARDT, 1993) 
y por algunos investigadores del campo, como el último de los grandes pedagogos (NARODOWSKI, 1997).

La bibliografía sobre Paulo Freire es amplísima, de tal modo que pretender decir algo novedoso sobre su trabajo y, en particular, sobre su pedagogía del oprimi$d o$, resulta una empresa muy arriesgada ${ }^{1}$. Consciente de ello, asumo este riesgo teniendo en mente dos objetivos: primero, uno de carácter personal: revisitar la obra a partir de la cual se abrió para mi un horizonte de estudio y de trabajo profesional hace casi cuarenta años; segundo, uno de carácter público: la conmemoración de los cincuenta años de su primera edición. Con este escrito, me propongo, entonces, examinar algunos conceptos de la pedagogía del oprimido cuya elección está relacionada con su resonancia en los estudios que he realizado durante la última década. En ese sentido, es una elección interesada, es decir, no busca ser objetiva y, por ese motivo, el análisis desarrollado no tiene una pretensión de fidelidad, lo que no significa un manejo descuidado de los conceptos y su respectivo contexto. No obstante, es necesario señalar que no hay aquí un intento de esclarecer qué fue lo quiso decir Freire con tal o cual término, sino de explorar cómo esos conceptos se pueden articular con el amplio horizonte conceptual de la pedagogía ${ }^{2}$, y en ese sentido, cuál es su potencia pedagógica, es decir, en qué consiste su carácter "antropotécnico"s.

\section{Sobre el carácter pedagógico de la pedagogía del oprimido}

Al parecer, la calificación de la pedagogía de Freire como "del oprimido" le otorga a su propuesta un marcado carácter político, de ahí que sea considerada como una verdadera ruptura con las tradiciones pedagógicas modernas. En la medida en que coloca la acción educativa en una dimensión netamente política, evidente en su propio objetivo (la liberación de los oprimidos), la pedagogía del oprimido sería, entonces, una teoría práctica (qué, cómo y por qué) de la revolución, es decir, de la transformación radical de la actual sociedad opresora. Consecuentemente con ello, el educador progresista es considerado un líder revolucionario ysu acción fundamentalmente política, pues su papel consistiría en la creación de las condiciones, conjuntamente con los oprimidos, en las cuales sea posible su concientización y, por tanto, su liberación y humanización.

Considero que la anterior línea de análisis, compartida por la mayoría de sus seguidores, ha debilitado la propuesta pedagógica de Freire y, en muchas ocasiones, ha llevado a substituir la acción educativa (liberadora) por un activismo po- 
lítico, y en el peor de los casos, por aquello que el propio Freire rechazaba: por la "esloganización, por la verticalidad, por los comunicados", pretendiéndose así "la liberación de los oprimidos con instrumentos de la domesticación” (FREIRE, 2005, p. 68). Aunque es evidente la apuesta política que tiene el análisis freireano de la educación, ello no debe ser un impedimento para percibir que es, en primer lugar y fundamentalmente, una apuesta pedagógica. Pero ¿qué significa decir que la pedagogía del oprimido es una apuesta pedagógica antes que política?

En primer lugar, significa reconocer que la obra freireana no es ajena a una tradición que se remonta a la antigüedad y según la cual existe la politeia es pensada como paideia, tradición que hoy podríamos calificar como una operación de "pedagogización de la política”. El primero en llevar a cabo esa operación fue Platón en La República, pero podríamos reconocer ese mismo gesto en el Emilio de Rousseau y, finalmente, en la pedagogía del oprimido donde Freire convierte la revolución social en un asunto "esencialmente pedagógico".

En segundo lugar, el libro de Freire constituye más una apuesta pedagógica que política, en la medida en que allí se entiende que la liberación sólo puede lograrse a través de una acción pedagógica cuyo sentido es hacer posible el paso de la conciencia ingenua hacia la conciencia crítica, es decir, únicamente puede alcanzarse la liberación mediante una acción sistemática y metódica - que exige un método - a través de la cual el sujeto pueda realizar el tránsito desde la doxa hacia el logos. Dicho en otras palabras: en tanto la liberación implica un proceso de concientización, su horizonte es de carácter gnoseológico, es decir, consiste en una acción realizada en clave epistémica.

En tercer lugar, reconocer el carácter pedagógico (antes que político) de la propuesta freireana significa entender que la educación es una condición fundamental para la humanización, puesto que la educación, en su sentido antropológico (no antropocéntrico), consiste en un conjunto de prácticas y técnicas cuyo propósito es "ser más" (FREIRE, 2005) o, usando otros términos y otro horizonte conceptual, el de la antropología filosófica, que la educación es la principal antropotécnica moderna, pues reconoce que al ejercer una gran "tensión vertical" en cada individuo se optimiza el estado inmunológico general de la humanidad (SLOTERDIJK, 2012).

A partir de estas tres comprensiones es posible, entonces, emprender la relectura de la pedagogía del oprimido en clave pedagógica. A continuación, se explicará en mayor detalle las implicaciones de cada uno de los anteriores enunciados en la perspectiva de mostrar que nuestro propósito no es redundante y sí muy necesario cuatro décadas después de la primera publicación de la obra. 


\section{La politeia como paideia}

Pedagogizar la acción política significa considerar que los medios y los fines políticos son, en lo fundamental, de carácter educativo. Quien primero realizó esta operación fue Platón en su un texto que, a pesar de su título (Politeia, generalmente traducido como La República), está dedicado a análisis de la educación como elemento fundamental de la organización social. Tal vez haya sido W. Jaeger (obra publicada originalmente en alemán en 1933) quien por primera vez planteó esta tesis que hoy siguen varios estudiosos. Según el filólogo alemán:

Su República no es una obra de derecho político o administrativo, de legislación o de política en el sentido actual [...] En última instancia, el estado de Platón versa sobre el alma del hombre. Lo que nos dice acerca del estado como tal y de su estructura, la llamada concepción orgánica del estado, en la que muchos ven la verdadera médula de la República platónica, no tiene más función que presentarnos "la imagen refleja ampliada" del alma y de su estructura. Y frente al problema del alma Platón no se sitúa tampoco en una actitud primariamente teórica, sino en una actitud práctica: en la actitud del modelador de almas. La formación del alma es la palanca por medio de la cual hace que su Sócrates mueva todo el estado. El sentido del estado, tal como lo revela Platón en su obra fundamental, no es otro que el podíamos esperar después de los diálogos que le preceden, el Protágoras y el Gorgias. Es, si nos fijamos en su superior esencia, educación. (JAEGER, 2010, p. 590-591).

En esa misma línea, décadas después E. Havelock (1994, obra publicada originalmente en 1963) insiste en que el título del texto platónico no debe llevarnos a engaño, pues sólo un tercio de la obra está dedicada a las cuestiones del Estado propiamente dichas. Por el contrario, a lo que apunta, fundamentalmente, ese texto clásico es a "un ataque al sistema educativo griego" (HAVELOCK, 1994, p. 27). Para Havelock el propósito de Platón es cuestionar el uso que los artistas hicieron de la poesía y la tragedia, por tanto, de la oralidad y la mimesis, como medios básicos para la educación del pueblo griego. En contraposición, con su República ideal Platón señala la importancia de la escritura y de la razón para la formación de un nuevo ciudadano que ya no esté constituido sobre la base del "embrujo de la memorización" (oralidad) sino en la psyche y la capacidad de cálculo razonado que implica dado su soporte en la escritura.

Con Emilio o de la educación Rousseau resaltó, nuevamente, la centralidad de la educación en la constitución de una nueva sociedad, pues para llegar a ella era preciso formar un nuevo hombre que, libre de los prejuicios de su tiempo y alejado de las perversiones de la civilización, asumiese la tarea de construir el nuevo pacto

social en sintonía con las leyes naturales. El título del libro tampoco debe engañarnos: no es sólo una novela sobre la educación de Emilio sino, además, un tratado 
político cuyo antecedente es, justamente, la República platónica ${ }^{4}$ Y a pesar de las consideraciones de algunos filósofos y de investigadores de las ciencias sociales, habría que recordar las palabras del propio Rousseau sobre su libro:

Jamás hubo publicación alguna que obtuviese tantos elogios particulares, ni tan poca aprobación del público. Lo que de ella me dijeron, lo que me escribieron las personas más capaces de juzgarla, me confirmaron en la creencia de que esta era la mejor y más importante de mis obras (ROUSSEAU, 1999, p. 525).

La crítica más contundente a la civilización de su tiempo, a los hombres de su época, está en el Emilio, pero también allí está su propuesta de restauración de la humanidad. La reforma social no se llevará a cabo mediante una transformación de orden político sino educacional: solo la transformación radical de la educación podrá llevar a la transformación radical de la sociedad. El nuevo hombre destinado a instaurar la nueva sociedad no podrá salir de la vieja escuela ni se formará mediante una enseñanza rigurosa: es por la educación que desde entonces se vincula íntimamente con las ideas de naturaleza, libertad e interés del "agente" (infante) que aprende en un "medio" especialmente adaptado para tal fin. Emilio no es el príncipe para el que escribió Erasmo, ni el gentleman del que se ocupó Locke en sus Pensamientos acerca de la educación. Emilio es el nuevo hombre, la nueva humanidad que nacerá de la educación (NOGUERA, 2012).

La pedagogía del oprimido es la siguiente obra de importancia en la línea que considera la politeia como paideia, aquella que se traza desde Platón, pasa por Rousseau, y se actualiza en Freire. El propio pedagogo brasileño señala explícitamente que con su propuesta educativa solo pretende "defender el carácter eminentemente pedagógico de la revolución” (FREIRE, 2005, p. 71) o, en otros términos, "defender el proceso revolucionario como una acción cultural [acción educativa] dialógica que se prolonga en una revolución cultural, conjuntamente con el acceso al poder" (2005, p. 208).

Entender la politeia como paideia significa no solo reconocer el estrecho vínculo entre una y otra, no solo percibir el carácter político de la educación, sino más allá de esos hechos evidentes, percatarse del papel central que tiene la educación en el proceso de humanización de todos y cada uno. Reconocer nuestra condición de "animales políticos" es percatarse que necesitamos de los otros para poder vivir, pero también, es recordar que vivir con los otros no es algo que se encuentre programado en nuestros genes, sino algo que debemos conseguir con cierto trabajo especializado, prolongado y arduo. Somos animales políticos porque necesitamos construir lazos con los otros: la politeia solo puede ser resultado de la paideia. 


\section{La concientización como una cuestión gnoseológica}

No puede haber proceso revolucionario sin una "toma de conciencia" del estado de opresión, por esa razón, Freire (2005, p. 71) insiste en que la acción revolucionaria es una acción educativa:

Si los lideres revolucionarios de todos los tiempos afirman la necesidad del convencimiento de las masas oprimidas para que acepten la lucha por la liberación - lo que por otra parte es obvio -, reconocen implícitamente el sentido pedagógico de esa lucha. Sin embargo, muchos, quizás por prejuicios naturales y explicables contra la pedagogía, acaban usando, en su acción, métodos que son empleados en la "educación" que sirve al opresor.

No obstante, parece que los prejuicios contra la pedagogía no son sólo asunto de los líderes revolucionarios. Aquellos educadores que ven en la pedagogía del oprimido, principalmente, una apuesta política, en alguna medida aminoran la acción pedagógica en el proceso liberador y, de esa manera, abren la posibilidad deusar "la propaganda para convencer..." (p. 71). En este punto, las precisiones (pedagógicas) de Freire son contundentes; que el proceso revolucionario sea una acción educativa significa, entonces, dos cosas: 1) que se trata de un asunto gnoseológico y 2) que implica un método.

En relación con el primer aspecto dice Freire (2005, p. 93):

Por el mismo hecho de constituirse esta práctica educativa en una situación gnoseológica, el papel del educador problematizador es el de proporcionar, conjuntamente con los educandos, las condiciones para que se dé la superación del conocimiento al nivel de la "doxa" por el conocimiento verdadero, el que se da al nivel del "logos".

En otras palabras, en tanto acción educativa, el proceso de liberación implica un acceso al conocimiento o, más precisamente, un paso de la doxa hacia el logos. A ese paso o transcurso Freire lo llama "concientización" y le otorga el carácter de finalidad de toda educación (FREITAS, 2010). Únicamente a través de la concientización se adquiere la "conciencia crítica", pero esta no es el efecto de la propaganda, los eslóganes y los comunicados, por más revolucionarios que se pretendan: la construcción de la conciencia crítica exige una investigación y lectura del mundo que se presenta como el universo temático de una época. Dice Freire (2005, p. 125):

Una unidad epocal se caracteriza por el conjunto de ideas, concepciones, esperanzas, dudas, valores, desafíos, en interacción dialéctica con sus contrarios, en búsqueda de la plenitud. La representación concreta de muchas de estas ideas, de estos valores, de estas concepciones y esperanzas, así como los obstáculos al ser más de los hombres, constituyen los temas de la época. 
La conciencia crítica expresa, entonces, la posibilidad de leer ese "universo temático de la época", lo que, a su vez, significa que el oprimido está en capacidad de emerger de su "situación" e insertarse en la realidad que va descubriendo. Emerger de la situación en que se encuentra implica un distanciamiento, una abstracción que sólo se puede hacer posible mediante un acto gnoseológico. Como toda acción educativa, la educación liberadora tiene un contenido programático en correspondencia con el "universo temático de la época": para la alfabetización, el programa educativo gira alrededor de las "palabras generadoras", mientras que, en la post-alfabetización, el eje está constituido por los "temas generadores". La determinación del contenido programático, es decir, la determinación de las palabras y de los temas generadores, es un trabajo de investigación que se desarrolla en varias etapas en las que toma parte un equipo interdisciplinario conjuntamente con miembros de la población que participará en la acción educativa. De esa investigación resulta, tanto la elaboración de las codificaciones (representación de situaciones existenciales con gran potencial analítico y crítico) a partir de las cuales se desarrollará el proceso de decodificación con los educandos, cuanto la "reducción" de los temas, labor de sistematización del trabajo realizado en los "círculos de investigación", a cargo de los especialistas participantes en el proceso. Sobre esta última parte de la investigación, dice Freire (2005, p. 153):

En el proceso de reducción de éste [el tema], el especialista busca sus núcleos fundamentales que, constituyéndose en unidades de aprendizaje y estableciendo una secuencia entre sí, dan la visión general del tema "reducido". En la discusión de cada proyecto específico se van anotando las sugerencias de varios especialistas. Éstas, ora se incorporan a la "reducción" en elaboración, ora constarán de pequeños ensayos a ser escritos sobre el tema "reducido". Estos pequeños ensayos, a los que se adjuntan sugerencias bibliográficas, son valiosas ayudas para la formación de los educadores-educandos que trabajarán en los "círculos de cultura".

Vinculado estrechamente con el carácter gnoseológico de la educación liberadora se encuentra la necesidad de un método. En otras palabras, alcanzar un grado de racionalidad, pensar lógicamente, críticamente, requiere de un trabajo metódico que es la base de la educación liberadora. El pensamiento mágico y la conciencia ingenua son distorsiones de la realidad que sólo la educación puede superar. La conciencia crítica implica racionalidad, lógica, por tanto, una perspectiva capaz de entender el mundo en términos de causalidad y no simple casualidad. En ese sentido, el pensamiento mítico o la conciencia ingenua son lo opuesto a la conciencia y el pensamiento crítico: "Si el sentido mágico de la intransitividad implica una preponderancia de lo ilógico, lo mítico con lo cual se envuelve la conciencia fanática 


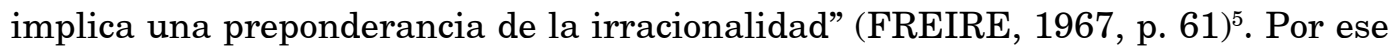
motivo, dice Freire (1967, p. 90): "Sólo podíamos comprender una educación que hiciese del hombre un ser cada vez más consciente de su transitividad, que en lo posible debe ser usada críticamente, o con un acento cada vez mayor de racionalidad”6. El problema fundamental del sentido mágico del mundo y de la conciencia ingenua de las masas es que impide la acción transformadora, pues sólo busca acomodarse a las circunstancias; en palabras de Freire (1997, p. 56), el problema "Es que, en la medida en que el hombre se comporta con base en mayor dosis de emocionalidad que de razón, en el sentido en que le da Barbu, su comportamiento no resulta comprometido sino acomodado".

De esa manera, la superación del sentido mágico y mítico, la superación de la comprensión ingenua del mundo, sólo puede hacerse a través de una acción metódica. Por este hecho la pedagogía del oprimido es pedagógica, por este hecho se vincula a la tradición pedagógica inaugurada por Comenio para quien la "salvación" de la humanidad tenía como condición la "erudición" (el conocimiento de todas las cosas) y, por tanto, una acción metódica que permitiese a todos los hombres conformarse como seres racionales, es decir, pasar de su mera condición animal para convertirse en verdaderamente humanos. Para Freire, la opresión significa una condición deshumanizante, hecho que justifica la educación problematizadora cuyo fin es la humanización. Pero, como hemos visto, la humanización -que no es una acción espontánea sino metódica - implica la adquisición de una conciencia crítica lo que significa la capacidad de leer el mundo, de ahí que la alfabetización no es un proceso mecánico de aprendizaje de la lectura y la escritura sino el desarrollo de la capacidad para leer y escribir el mundo, esto es, su comprensión y transformación.

El método se constituye en el eje de la pedagogía del oprimido. Recordemos que el propio Freire en sus "palabras preliminares" nos aclara que su libro no consiste en devaneos intelectuales, es decir, no es una cuestión teórica, sino una teoría-práctica. También nos previene sobre la posible confusión de la propaganda y esloganización con la educación liberadora: la propaganda y la construcción de lemas para incitar la acción liberadora de los oprimidos requieren de técnicas retóricas para conseguir efectividad, pero la educación liberadora necesita de un método porque la superación del sentido mágico y mítico del mundo no es un acto espontáneo ni el resultado de una "toma de conciencia" efecto de una buena propaganda. Como se trata de un proceso de concientización, no puede separarse de un método. Freire (2005, p. 73), citando a Vieira, afirma al respecto: 
En verdad - señala el profesor Álvaro Vieira Pinto -, el método es la forma exterior y materializada en actos, que asume la propiedad fundamental de la conciencia: la de su intencionalidad. Lo propio de la conciencia es estar con el mundo y este proceso es permanente e irrecusable. Por lo tanto, la conciencia en su esencia es un "camino para", algo que no es ella, que está fuera de ella, que la circunda y que ella aprehende por su capacidad ideativa. Por definición, continua el profesor brasileño, la conciencia es método, entendido este en su sentido de máxima generalidad. Tal es la raíz del método, así como tal es la esencia de la conciencia que sólo existe en tanto facultad abstracta y metódica.

Mientras en la pedagogía del oprimido Freire explica el método para la determinación de los temas generadores, en su obra anterior -La educación como práctica de la libertad-dedica un capítulo a señalar las etapas o fases de su método de alfabetización que se pueden resumir de la siguiente manera: 1) obtención del universo del vocabulario de los grupos con los cuales se trabajará; 2) selección del universo del vocabulario estudiado según su riqueza y dificultades fonéticas y el tenor pragmático de la palabra; 3) la creación de situaciones existenciales típicas (y desafiantes) del grupo con el que se va a trabajar; 4) elaboración de fichas que ayuden a los coordinadores (educadores) en su trabajo; 5) preparación de fichas con la descomposición de las familias fonéticas que corresponden a los vocablos generadores (FREIRE, 1997).

¿Será necesario recordar que la alfabetización es el desarrollo de la capacidad crítica de leer y escribir el mundo? Creo que es necesario recordarlo hoy cuando algunas posiciones-en su crítica a los efectos negativos de la racionalidad del pensamiento occidental- rechazan la racionalidad y niegan sus potencialidades a la vez que celebran un supuesto "pensamiento ancestral", originario y salvador. Desde luego, no son posturas académicas sino militantes, pero tienen alguna resonancia en los programas de formación de profesores, por ello, es preciso hoy leer a Freire nuevamente y leerlo a la luz del horizonte conceptual de la pedagogía y, por tanto, no olvidar que se trata de una perspectiva donde el conocimiento lógico, racional, ocupa lugar central. Vale la pena recordar aquí, nuevamente, el giro platónico de la doxa hacia el logos que evoca Freire en su pedagogía del oprimido, pues al decir de Havelock, se trata de la inauguración de una nueva tecnología de la comunicación (educación):

Los signos escritos, viniendo en ayuda de la memoria, permitían que el lector se desentendiera en buena medida de toda la carga emocional inherente al proceso de identificación -único capaz de garantizar el recuerdo dentro de los límites del registro acústico-. Con ello quedaba disponible cierta cantidad de energía psíquica, que ahora podía consagrarse a la revisión y reorganización de lo escrito; lo cual se percibía ya no sólo como algo escuchado y sentido, sino como algo susceptible de convertirse en objeto. Se hizo posible, por así decirlo, volver a mirar, echar un segundo vistazo (1994, p. 196). 
En esa misma dirección, Goody (2008), apartándose de la distinción problemática proveniente de la antropología entre pensamiento primitivo o salvaje y pensamiento racional, opta por la distinción entre diferentes tecnologías de la comunicación que tiene, a su vez, implicaciones en las manera de pensar, de ahí su afirmación de que: “[...] la escritura no es mero registro fonográfico del habla como Bloomfield (y otros) han asumido; al depender de condiciones sociales a la vez que tecnológicas, estimula formas especiales de actividad lingüística asociadas a desarrollos particulares de plantear problemas y de resolverlos; en las que la lista, la fórmula y la tabla jugaron una parte fecunda (p. 181). Cuando Freire destaca la importancia que tiene la "codificación" de las situaciones existenciales concretas de los oprimidos y en su posterior "decodificación” en el proceso de concientización, no hace otra cosa que subrayar su papel en la construcción de formas críticas de "lectura" del mundo: "Las codificaciones no son marbetes, son objetos cognoscibles, desafíos sobre los que debe incidir la reflexión crítica de los sujetos descodificadores" (2005, p. 145). Inicialmente las codificaciones no son palabras sino fotografías o ilustraciones, pero son la primera aproximación a la lectura del mundo. Desde luego, en la oralidad, en la palabra dicha está ya presente un proceso de humanización del mundo, pero como aclara lúcidamente Fiori (2005, p. 25) en su prólogo a la pedagogía del oprimido:

Es verdad: ni la cultura iletrada es la negación del hombre, ni la cultura letrada llegó a ser su plenitud. No hay hombre absolutamente inculto: el hombre se "hominiza" expresando y diciendo su mundo. Ahí comienza la historia de la cultura. Mas, el primer instante de la palabra es terriblemente perturbador: hace presente el mundo a la conciencia y, al mismo tiempo, lo distancia. El enfrentamiento con el mundo es amenaza y riesgo [...] En un comportamiento ambiguo, mientras ensaya el dominio técnico de ese mundo, intenta volver a su seno, sumergirse en él, enredándose en la indistinción entre palabra y cosa. La palabra, primitivamente, es mito.

[...] En esa ambigüedad con que la conciencia hace su mundo, apartándolo de sí, en el distanciamiento objetivamente que lo hace presente como mundo consciente, la palabra adquiere la autonomía que la hace disponible para ser recreada en la expresión escrita. Aunque no haya sido un producto arbitrario del espíritu inventivo del hombre, la cultura letrada es un epifenómeno de la cultura que, al actualizar su reflexividad virtual, encuentra en la palabra escrita una manera más firme y definida de decirse, esto es, de existenciarse discursivamente en la "praxis" histórica. Podemos concebir la superación de las letras; lo que en todo caso quedará es el sentido profundo que la cultura letrada manifiesta: escribir no es conversar y repetir la palabra dicha, sino decirla con la fuerza reflexiva que su autonomía le da a su fuerza ingénita que la hace instauradora del mundo de la conciencia, creadora de cultura. 


\section{La humanización como justificación de la pedagogía del oprimido}

La pedagogía del oprimido es más antropológica que política. Nuevamente debo insistir en que no se trata de restar importancia a la obvia dimensión política de la pedagogía freireana, sino resaltar el menos obvio, tal vez sería mejor decir, el oculto o invisible, carácter antropológico (antropotécnico) de su pedagogía. Fiori (2005, p. 17) en su presentación del libro de Freire afirma:

Con la palabra el hombre se hace hombre. Al decir su palabra, el hombre asume conscientemente su esencial condición humana. El método que le propicia ese aprendizaje abarca al hombre todo, y sus principios fundan toda la pedagogía, desde la alfabetización hasta los más altos niveles del quehacer universitario.

La educación reproduce de este modo, en su propio plano, la estructura dinámica y el movimiento dialéctico del proceso histórico de producción del hombre. Para el hombre producirse es conquistarse, conquistar su forma humana. La pedagogía es antropología.

Para evitar confusiones, podríamos decir que toda pedagogía es antropogogía, así como toda acción educativa en una acción antropotécnica. La pedagogía (y la educación) se justifican por el carácter inacabado y abierto del ser humano. A lo largo de su libro, Freire recurre a la antropología para señalar el carácter cerrado de los animales y resaltar la condición inconclusa y abierta de lo humano. El hombre tiene que hacerse y para ello cuenta con una "vocación de humanización". Pero esa vocación no puede confundirse con la condición biológica que implica el cuidado y socialización de los niños. La vocación de humanización es una tendencia permanente del ser humano, pues es un impulso de ser más:

Los hombres, diferentes de los otros animales que son sólo inacabados mas no históricos, se saben inacabados. Tienen consciencia de su inconclusión.

Así se encuentra la raíz de la educación misma, como manifestación exclusivamente humana. Vale decir, en la inconclusión de los hombres y en la consciencia que de ella tienen. De ahí que sea la educación un quehacer permanente. Permanente en razón de la inconclusión de los hombres y del devenir de la realidad (FREIRE, 2005, p. 97).

Ahora bien, esa tendencia puede verse obstaculizada (intencionalmente o no) y dar lugar a un proceso contrario de deshumanización que sería una tendencia a ser menos. En ese sentido, la historia de la humanidad podría leerse en clave de procesos diversos de humanización y deshumanización. Los primeros filósofos y sofistas griegos inventaron la areté como el grado máximo de excelencia a la cual podían aspirar los hombres, siempre y cuando se sometieran a un proceso técnico y artístico (filosofía y sofística). Se trata de un ser más que, por primera vez en la historia, se pensó como posibilidad para todos los "ciudadanos", pues hasta entonces la areté se 
consideraba como una cuestión vinculada a la nobleza de sangre. Pero fue en el siglo XVII donde la "vocación de humanización" dio su fruto más maduro: por primera vez en la historia de la humanidad se pensó, no sólo que era posible sino necesario, "enseñar todo a todos" para la salvación ${ }^{7}$ de la humanidad. Comenio encarna una "voluntad" de humanización que pasa por la erudición (conocimiento de las cosas) y aspira a la configuración de un ser racional, pero a la vez, virtuoso y piadoso ${ }^{8}$.

Al definir al ser humano como un animal disciplinable, reconoce su posibilidad de ser más a través de la disciplina que significa capacidad de aprender y ser enseñado. Ser disciplinable, entonces, significa una potencia que debe actualizarse con la ejercitación; no basta crecer y desarrollarse para adquirir la condición humana. La idea radical de Comenio es que la gran mayoría de la humanidad ha vivido en un estado animal, pues no ha conseguido ser más, o en sus términos, no ha llegado a la erudición, la virtud y la piedad. Podríamos decir que en lugar de humanización a través de los siglos ha imperado un largo proceso de deshumanización que ha mantenido a los humanos incapaces de alzarse sobre su condición de animalidad. La didáctica fue pensada como el arte de las artes, es decir, como un arte magno, pues su propósito es la formación de verdaderos humanos.

Freire considera que el problema de la humanización, pese haber sido el problema central de la humanidad, "asume hoy el carácter de preocupación ineludible" (2005, p. 39), pues la realidad histórica de opresión y explotación que impide a las masas ser más, constituye un proceso de deshumanización. La pedagogía del oprimido se justifica, entonces, como la posibilidad de conseguir la emancipación, pero esa emancipación debe leerse, también, en clave pedagógica, lo que significa no considerar únicamente la opresión en términos políticos y económicos. Pedagógica o antropológicamente la opresión y la explotación significan la negación de la posibilidad de mundo que se traduce en deshumanización, pues, a diferencia del animal que vive en un hábitat, el hombre vive en el mundo. En cuanto ser cerrado en sí mismo, el animal vive inmerso en su hábitat que es simple "soporte" al que se adapta para satisfacer sus necesidades, su hábitat no es problemático sino tan sólo estimulante:

$\mathrm{Su}$ vida no es un correr riesgos, en tanto que no sabe que los corre. Estos, dado que no son desafíos percibidos reflexivamente sino meramente "notados" por las señales que los apuntan, no exigen respuestas que impliquen acciones de decisión. Por esto mismo, el animal no puede comprometerse. Su condición de ahistórico no le permite asumir la vida. Y, dado que no la asume, no puede construirla. Si no la construye, tampoco puede transformar su contorno. No puede, tampoco, saberse destruido en vida, puesto que no consigue prolongar el soporte donde ellas se da: en un mundo significativo y simbólico, el mundo comprensivo de la cultura y de la historia. Ésta es la razón por la cual el animal no animaliza su contorno para animalizarse, ni tampoco se desanimaliza (FREIRE, 2005, p. 120). 
La condición de opresión y explotación en que viven los oprimidos es como la condición del animal en su contorno: está enfrentado a situaciones-límite "que se presentan a los hombres como si fuesen determinantes históricos, aplastantes, frente a las cuales no les cabe otra alternativa sino adaptarse a ellas" (p. 126). Únicamente a través de la educación (liberadora) los oprimidos podrán, ante las que consideraban situaciones-límite, producir "actos límite", es decir, acciones "que se dirigen a la superación y negación de lo otorgado, en lugar de implicar su aceptación dócil y pasiva” (p. 122). La educación es, en ese sentido, una lectura y una escritura del mundo, una construcción de mundo, acto de humanización de su "contorno" para convertirlo en mundo.

Pedagogía como "antropogogía", politeia como paideia: esas fueron las claves que utilicé para releer la pedagogía del oprimido. Creo no haber distorsionado el sentido del texto, por el contrario, me parece que tan sólo he tratado con este escrito recuperar la pedagogía en la pedagogía del oprimido: ese es mi homenaje a Paulo Freire.

\section{Notas}

1 Entre los innumerables trabajos sobre Paulo Freire hay que destacar el elaborado por el Instituto Paulo Freire (publicado en portugués en 1996) y titulado "Paulo Freire. Una biobibliografía", editado por Siglo XXI Editores en el 2001 en donde se realiza un análisis detallado de sus libros y de las principales obras escritas sobre Freire.

2 ZULUAGA (1999, p. 50) denominó horizonte conceptual de la pedagogía "El conjunto de objetos producidos en el discurso pedagógico, cuando este alcanza un estatuto de saber así delimitado: un conjunto de objetos a los cuales se refieren sus elaboraciones ya teóricas, ya prácticas, alcancen o no un estatuto de 'cientificidad'; las diversas formas de enunciación por parte de los sujetos que entran en relación con estos de manera directa o indirecta: un conjunto de nociones que también circulan por otros dominios de saberes, pero que se agrupan o reagrupan a propósito de aquellos objetos y de las formas de enunciarlos; los procesos de adecuación y apropiación social para su existencia y control institucional y para la selección de los sujetos reconocidos socialmente como sujetos portadores de ese saber".

3 A mi modo de ver, este concepto utilizado por el filósofo alemán Peter Sloterdijk en sus obras más recientes, es de gran importancia para el campo de estudios pedagógicos, en la medida en que, desde una revisión de la historia de la filosofía y, apoyándose en una perspectiva antropológica, destaca el papel de las prácticas de constitución o formación de seres humanos, vinculando, de esta manera, filosofía, pedagogía y antropología en sus análisis. Sloterdijkusó ese término por primera vez en su polémica conferencia de 1999 titulada "Reglas para el parque humano" (2011) para referirse al conjunto de instrumentos y prácticas que los hombres utilizan para su crianza, domesticación y producción. Una década después (2009), en su libro titulado en español "Has de cambiar tu vida" (publicado en 2012), el filósofo alemán avanza en la elaboración del concepto antropotécnicas al referirlo a los procedimientos de ejercitación tanto de tipo corporal como mental con los que los hombres de las diversas culturas "han intentado optimizar su estado inmunológico frente a los vagos riesgos de la vida y las agudas certezas de la muerte" (SLOTERDIJK, 2012, p. 24). Sobre la base de esta definición, y a través de sus cerca de 600 páginas, Sloterdijk emprende la construcción de una "teoría general del ejercicio" apoyándose para ello en la idea nietzscheana del humano como un ser ejercitante y de la Tierra como el astro ascético. 
$4 \mathrm{Al}$ respecto escribe Rousseau en su Emilio: “¿Queréis tener una idea acerca de la educación pública? Leed la República de Platón. No es una obra política, como piensan los que sólo juzgan los libros por sus títulos. Es el tratado de educación más hermoso que jamás se haya hecho" (ROUSSEAU, 2011, p. 49).

5 Hago aquí una traducción del texto original en portugués, pues la traducción castellana es imprecisa al punto que señala todo lo contrario de lo que afirma Freire, como se evidencia aquí: "Si el sentido mágico y la transitividad implican una preponderancia de la lógica, lo místico con lo cual se envuelve la conciencia fanática implica una preponderancia de la irracionalidad" (FREIRE, 1997, p. 57. Traducción de Lilién Ronzoni. Resaltado mío).

${ }^{6}$ Nuevamente prefiero traducir el texto directamente de la edición del portugués. Sobre el término racionalidad, Freire aclara en un pie de página que utiliza esa expresión en el sentido que le da K. Popper cuando afirma: "Lo que llamo verdadero racionalismo es el racionalismo de Sócrates. Es la conciencia de las propias limitaciones, la modestia intelectual de quienes que saben cuantas veces yerran y cuanto dependen de los otros para obtener ese conocimiento". Popper. K. A sociedade democrática e seus inimigos.

7 Vale la pena tener en cuenta que esta palabra viene del latín salvēre o salvāre que significa colocar en buen estado, intacto, con salud. Significa librar de algún peligro, evitar un impedimento, problema, obstáculo; vencer una dificultad.

8 "El nombre de erudición comprende el conocimiento de todas las cosas, las artes y las lenguas; el de buenas costumbres [o virtud], no solo la externa urbanidad, sino la ordenada disposición interna y externa de nuestras pasiones; y con el de Religión se entiende aquella interna veneración por la cual el alma del hombre se enlaza y une al Ser Supremo" (COMENIO, 1984, p. 9).

\section{Referencias}

COMENIO, J. Didáctica Magna. México: Porrúa, 1984.

FIORI, E. Aprender a decir su palabra. El método de alfabetización del profesor Paulo FREIRE. In: FREIRE, P. Pedagogía del oprimido. México: Siglo XXI, 2005. p. 11-27.

FREIRE, P. Educação como prática da liberdade. Rio de Janeiro: Paz e Terra, 1967.

FREIRE, P. La educación como práctica de la libertad. México: Siglo XXI, 1997.

FREIRE, P. Pedagogía del oprimido. México: Siglo XXI, 2005.

FREITAS, A. Conscientização. In: STRECK, D.; REDIN, E.; ZITKOTSKI, J. (org.). Dicionário Paulo Freire. Belo Horizonte: Autêntica, 2010.

GERHARDT, H. Paulo Freire. Perspectivas, v. xxiii, n. 3-4, p. 463-484, 1993.

GOODY, J. La domesticación del pensamiento salvaje. Madrid: Akal, 2008.

HAVELOCK, E. Prefacio a Platón. Madrid: Visor, 1994.

JAEGER, W. Paideia: los ideales de la cultura griega. México: Fondo de Cultura Económica, 2010.

NARODOWSKI, M. Freire: el último de los grandes pedagogos. Novedades educativas, 78, 1997.

NOGUERA, C. El gobierno pedagógico. Del arte de educar a las tradiciones pedagógicas. Bogotá: Siglo del Hombre - GHPP, 2012.

ROUSSEAU, J. Las confesiones. Madrid: Conacultura - Océano, 1999. 
SLOTERDIJK, P. Reglas para el parque humano. In: SLOTERDIJK, P. Sin salvación. Tras las huellas de Heidegger. Madrid: Akal, 2011. p. 197-220.

SLOTERDIJK, P. Has de cambiar tu vida. Pre-Textos, 2012.

ZULUAGA, O. Pedagogía e historia. Bogotá: Anthropos-Siglo del Hombre, 1999. 